\title{
Reflections on Another Pandemic
}

Gail Levine, MD

As we are faced with the Covid-19 pandemic, we reflect back to another pandemic disease with devastating consequences, fearful to the population, without treatment, and with the population looking hopefully towards the development of a vaccine.

Poliomyelitis infections have likely been with humankind since antiquity, as described in images and historical accounts. Polio was an endemic pathogen until the 1900s when the United States and Europe began to see epidemics. (1) Jakob Heine published the first medical article about polio in 1840. In 1890 Karl Oskar Medin was the first to study a poliomyelitis epidemic. The disease was, therefore, then called Heine-Medin disease. $(2,3)$

Before 1900, polio infections mostly occurred in children six months to four years of age. (4) Only mild symptoms generally resulted from infection in this age group and resulted in immunity. (5) Around the turn of the century, there were improvements in clean water and sewage disposal, and this younger age group had less exposure to poliovirus. Poliovirus exposure was thereby delayed until later childhood and adulthood. At these ages, we are more at risk for the paralytic form. (4)

\section{"1952 brought the nation's most severe epidemic, with over 57,000 cases, over 21,000 with mild to severe paralysis, and 3145 deaths. $(7,8)^{\prime \prime}$}

Epidemics caused widespread fear, closure of movie theatres, and cancellation of meetings and public gatherings. Children were told not to drink from water fountains; pools were closed. People stayed home. (6) 1952 brought the nation's most severe epidemic, with over 57,000 cases, over 21,000 with mild to severe paralysis, and 3145 deaths. $(7,8)$

John Enders, Thomas $\mathrm{H}$. Weller, and Frederick C Robbins successfully cultured the poliovirus in human tissue and were awarded the Nobel Prize in 1954. (9) This work enabled the development of the Salk vaccine, the inactivated polio vaccine. Testing took place in 1954. Vaccine campaigns followed licensing, promoted by the March of Dimes. In the US, the annual number of cases fell from a peak of 58,000 cases to 5600 cases. (3) Albert Sabin developed the oral polio vaccine with an attenuated live virus. It was licensed in 1962. Mass immunization with this vaccine further reduced cases to 161 in 1961. (10)

Franklin $D$ Roosevelt became paralyzed from the waist down by polio in 1921. In 1938 he helped to found the National Foundation for Infantile Paralysis, now known as the March of Dimes. The March of Dimes raised funds for rehabilitation of those with paralysis and contributed to funding the development and testing of the polio vaccines. The March of Dimes transformed philanthropy by soliciting small donations from individuals rather than only large contributions from the wealthy. A dime in 1950 was equivalent to $\$ 1.06$ in 2020. (11)

Poliovirus is a human enterovirus $C$ species, a single positivestrand RNA virus. (12) Poliovirus serotypes 1, 2, and 3 can all produce motor neuron disease. Most paralytic disease is due to Poliovirus 1. Wild poliovirus serotypes 2 and 3 no longer circulate. Pakistan and Afghanistan continue to report cases of wild poliovirus 1 poliomyelitis. (13)

Poliovirus is transmitted by fecal-oral spread, and in epidemics, by pharyngeal spread. (14) $90-95 \%$ of poliovirus infections are asymptomatic. In less than $10 \%$, a minor illness known as abortive polio follows an incubation period of 4-10 days. It can include symptoms of common viral infections. In some, there is a symptom-free interval of a few days, followed by CNS involvement. There are meningitic symptoms and signs, which may be followed by the destruction of anterior horn cell motor neurons and motor weakness. Only $0.1 \%$ of poliovirus infections lead to paralysis. $(15,16)$

Viral replication in spinal motor neurons leads to cell death and paralysis of the muscle tissue supplied by the motor neurons. Cranial nerve involvement can lead to dysphagia, and thoracic muscle involvement can lead to respiratory insufficiency. (17)

The polio pandemic led to advances in vaccine science and the transformation of philanthropy, as well as to developments in rehabilitation medicine. Many of its survivors became leaders in the disability rights movement.

\section{"We can be hopeful that similarly beneficial outcomes result from our current COVID-19 pandemic, whether that be an acceleration of research into therapeutics and vaccines, or improved preparedness for the next pandemic yet to emerge."}

We can be hopeful that similarly beneficial outcomes result from our current COVID-19 pandemic, whether that be an acceleration of research into therapeutics and vaccines, or improved preparedness for the next pandemic yet to emerge.

Philip Zweig, a friend of Neonatology Today, has shared with us his Polio Pioneer card. He took part in a trial of a polio vaccine in 1954. In 1954, this would have been the trial of the Salk inactivated polio vaccine. 
THE NATIONAL FOUNDATION FOR INFANTILE PARALYSIS CERTIFIES THAT

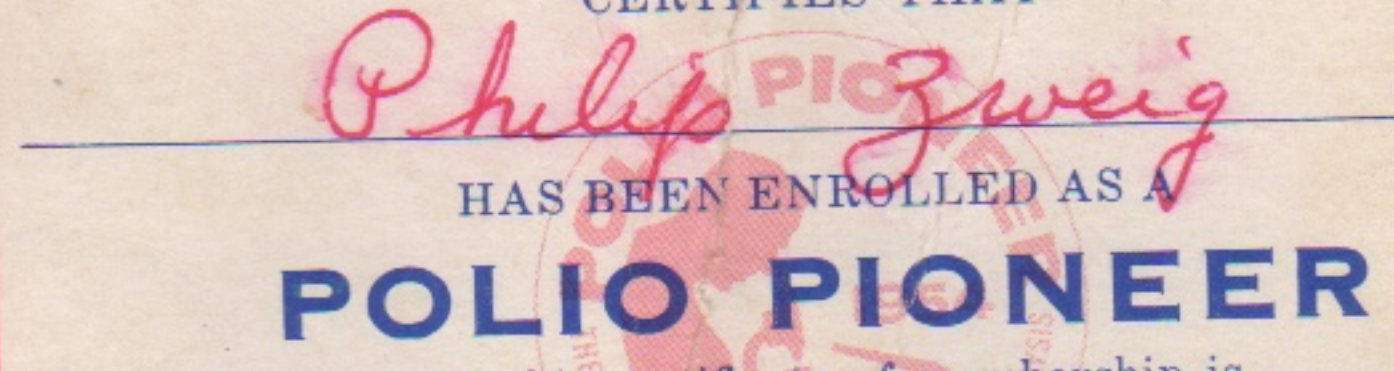

and this certificate of membership is

hereby presented for taking part in the first national tests

of a trial polio vaccine conducted during 1954 .
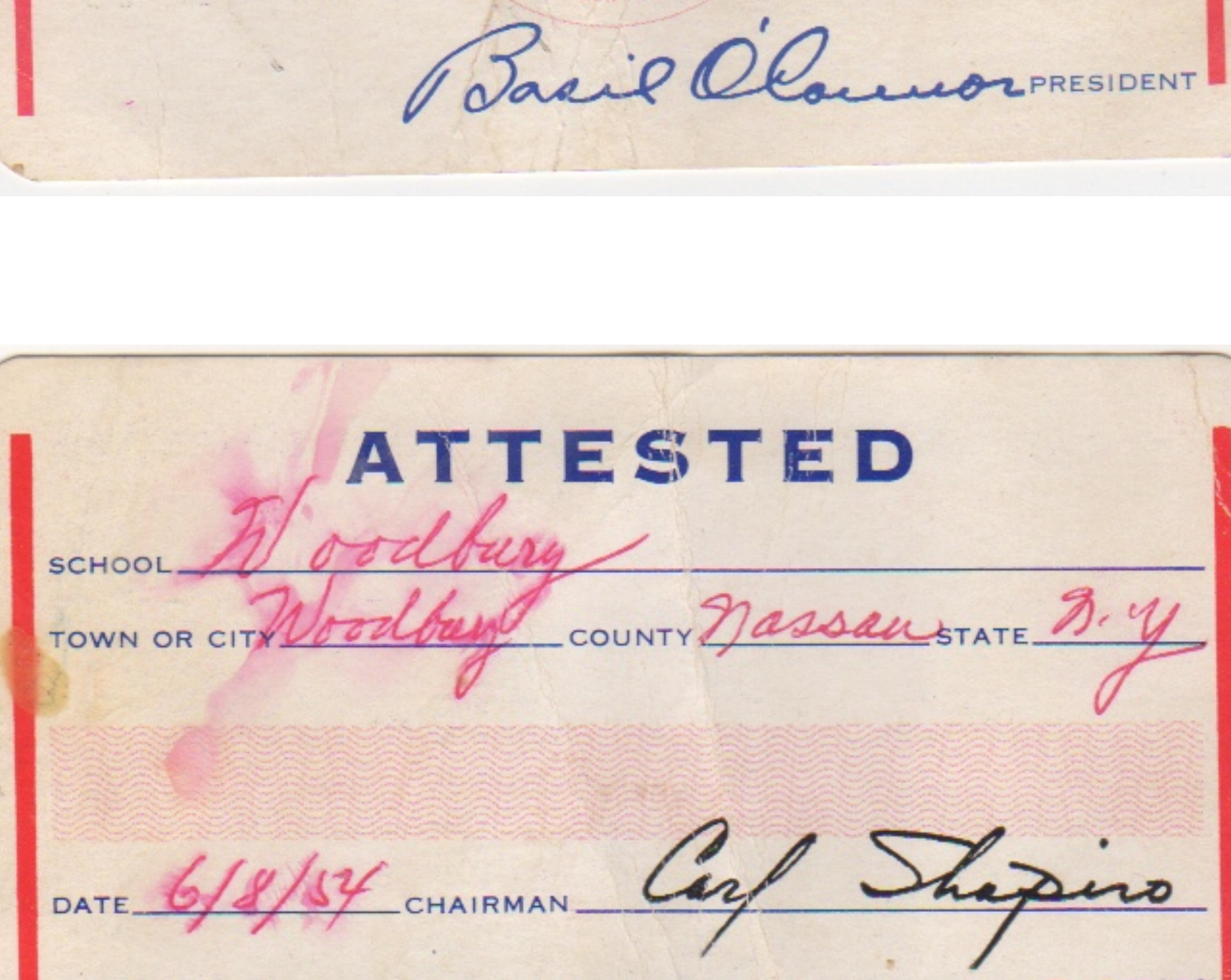

THE NATIONAL FOUNDATION FOR INFANTILE PARALYSIS 
References:

1. Trevelyan B, Smallman-Raynor M, CliffA (2005) "The Spatial Dynamics of Poliomyelitis in the United States: From Epidemic Emergence to Vaccine-Induced Retreat, 1910-1971' Ann Assoc Am Geogr. 95 (2): 269-293 PMID 16741562

2. Pearch $J$ (2005) "Poliomyelitis (Heine-Medin disease)" $J$ Neurol Neurosurg Psychiatry. 76 (1) 128 PMID 15608013

3. Sass, EJGottfried G, Sorem A, eds (1996) Polio's Legacy: an oral history. Washington, DC: University Press of America. ISBN 0-7618-0144-8.

4. Robertson, S (1993) "Module 6: Poliomyelitis The Immunological Basis for Immunization Series. World Health Organization. Geneva, Switzerland.

5. Yin-Murphy M, Almond JW (1996). Baron S et al. (eds) Picornaviruses: The Enteroviruses: Polioviruses in: Baron's Medical Microbiology (4th ed) Univ of Texas Medical Branch ISBN 0-9631172-1-1

6. Melnick J (1 July 1996). "Current status of poliovirus infections". Clin Microbiol Rev. 9 (3): 293-300 PMID 8809461

7. "History of Vaccines Website- Polio cases Surge" (http:// www.historyofvaccines.org/content/timelines/diseasesand-vaccines\#EVT 100309). College of Physicians of Philadelphia. 3 November 2010.

8. Zamula, Evelyn (1991). "Anew Challenge for Former Polio Patients" FDA Consumer. 25 (5).

9. "The Nobel Prize in Physiology or Medicine 1954" (http:// nobelprize.org/nobel prizes/medicine/laureates/1954/)The Nobel Foundation.

10. Hinman A (1984). "Landmark perspective: Mass vaccination against polio". JAMA. 251 (22): 2994-6. PMID 6371280.

11. Staff of the National Museum of American History, Behring Center. "Whatever Happened to Polio?" (http:// americanhistory.si.edu/polio/howpolio/march.htm)

12. Brown B, Obersie MD, Maher $K$, Pailanson MA. Completegenomic sequencing shows that polioviruses and members of human enterovirus species $C$ are closely related in the noncapsid coding region. J Virol 2003: 77;8973.

13. Hsu Ch, Kader M, Mahamud A, et al. Progress Toward Poliomyelitis Eradication- Pakistan, January 2018-September 2019. MMWR Morb Mortal Wkly Pep 2019: 68;1029

14. DeBiasi RL, Solbrig MV, Tyler KL. Infections of the nervous system: viral infections. In: Neurology in Clinical Practice, 4th ed, Bradley WG, Daroff RB, Fenichel GM, Jankovic J (Eds), Butterworth Heineman, Philadelphia 2004. P 1515

15. Modlin JF. Poliovirus. In: Mandell, Douglas, and Bennett's Principles and Practice of Infectious Diseases, 6th ed. Mandell GL, Bennett JE, Dolin R (Eds), Elsevier, Philadelphia
2005. P.2141.

16. Mueller S, Wimmer E, Cello J. Poliovirus and poliomyelitis: a tale of guts, brains, and an accidental event. Virus Res 2005; 111;175.

17. Jubelt $B$. Enterovirus infections. In: Viral infections of the Human Nervous System, Jackson AC (Ed), Springer Basel, 2013. P. 117.

The author has no conflicts to disclose

NT
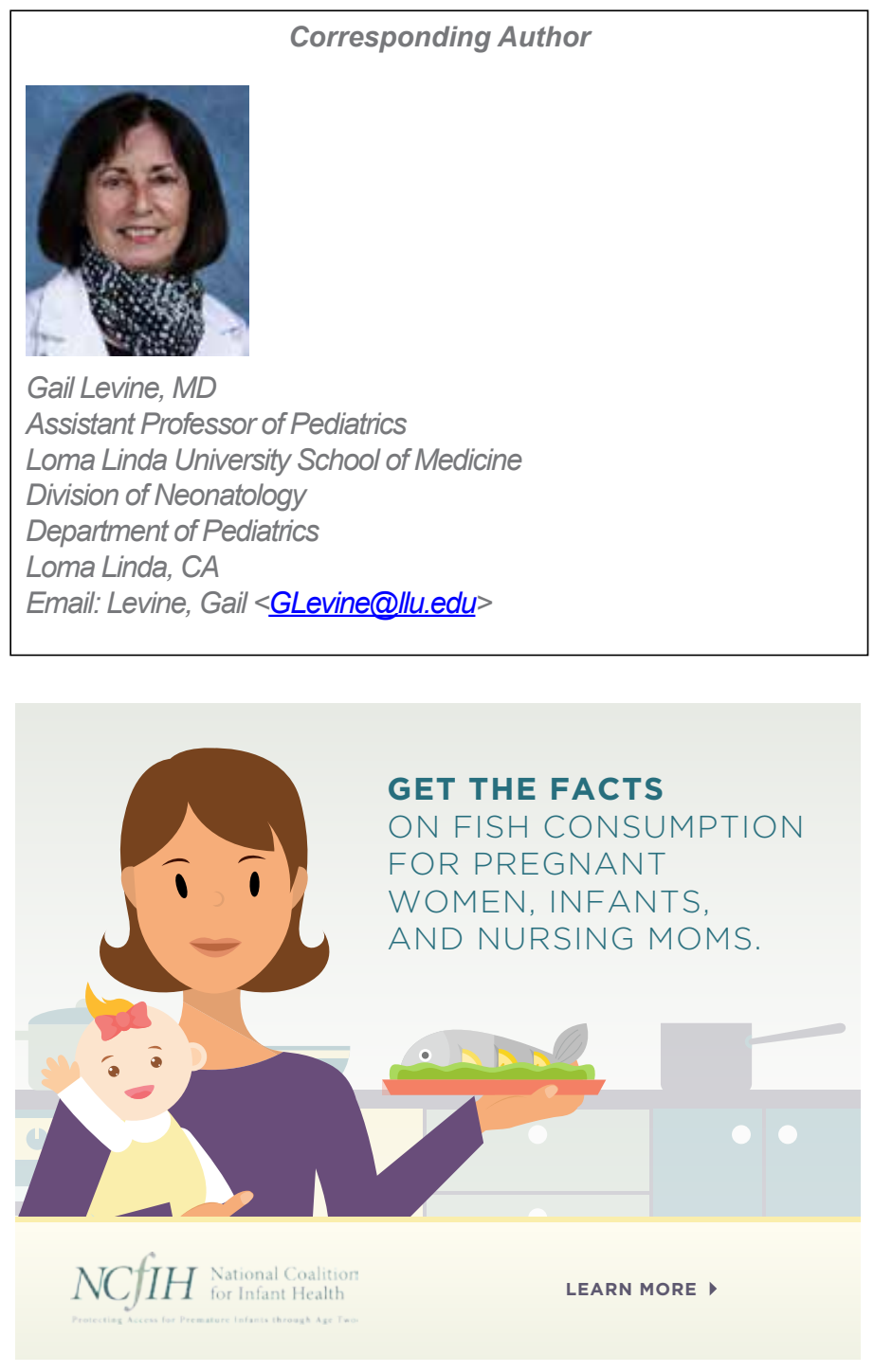

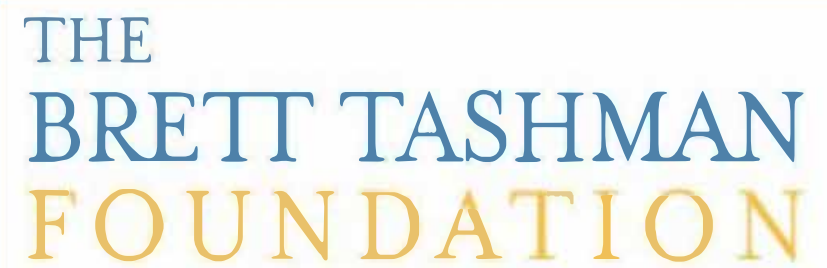

THE

BRETT TASHMAN

The Brett Tashman Foundation is a 501@(3) public charity. The mission of the Foundation is to find a cure for Desmoplastic Small Cell Round Tumors (DSRCT). DSRCT is an aggressive pediatric cancer for which there is no cure and no standard treatment. 100 percent of your gift will be used for research. There is no paid staff. To make your gift or for more information, go to "TheBrettTashmanFoundation.org" or phone (909) 981-1530. 